\title{
Intrarenal Blood Oxygenation and Renal Function Measured by Magnetic Resonance Imaging During Long-Term Cyclosporine Treatment
}

\author{
D.H. Kristensen, M. Pedersen, M.C. Grøn, A. Flyvbjerg, M. Madsen, J. Frøkiær, and J. Mortensen
}

\begin{abstract}
Treatment with cyclosporine (CsA) markedly affects the renin-angiotensin-aldosterone system in parallel with an increase in the net tubular reabsorption or a decrease in secretion. Since tubular reabsorption is closely linked to medullary oxygen consumption, the aim of the present study was to investigate the intrarenal oxygenation and renal function in response to CsA. Six mini Göttingen pigs were treated with CsA (10 mg/kg/d) for 6 months. The intrarenal oxygenation was indirectly measured as R2* obtained with a multiecho gradient-echo magnetic resonance imaging (MRI) sequence. Single-kidney renal blood flow (skRBF) was measured by a velocity-sensitive gradient-echo MRI sequence. Relative single-kidney glomerular filtration rate (rskGFR) was derived from the MRI time-activity curve in response to an intravenous bolus of Gd-DTPA $(0.05 \mathrm{mmol} / \mathrm{kg})$. The present study showed that administration of CsA increased the medullary R2* (23.1 $\mathrm{Hz}$ vs $19.0 \mathrm{~Hz}, P=.002)$, whereas R2* was slightly increased in the renal cortex $(13.3 \mathrm{~Hz}$ vs $12.3 \mathrm{~Hz}, P=.012)$. In parallel, rskGFR increased significantly $(47.2 \mathrm{~mL} / \mathrm{min}$ vs 19.8 $\mathrm{mL} / \mathrm{min}, P=.005)$ but skRBF was unchanged $(197.6 \mathrm{~mL} / \mathrm{min}$ vs $202.5 \mathrm{~mL} / \mathrm{min}, P>.05)$. The increased $\mathrm{R} 2 *$ in the renal medulla indicated that CsA augments the tubular reabsorption of water, leading to increased oxygen consumption. The supply of oxygen to the kidney was, however, maintained during treatment with CsA as suggested by an unchanged renal blood flow. The increased tubular reabsorption was compensated for by an elevated glomerular filtration rate.
\end{abstract}

$\mathrm{C}$ YCLOSPORINE (CsA), introduced in the early 1980s as a prophylaxic agent, has been successfully applied to prevent graft rejection following transplantation. It was first introduced to patients subjected to kidney transplantation, yielding a 1-year survival rate of $80 \%$ to $90 \% .^{1,2}$ Unfortunately several serious side effects of CsA treatment have been reported, including interstitial fibrosis and tubular atrophy accompanied by a progressive decrease in renal function. ${ }^{3,4}$ The indication for using CsA clinically has been widened during the last decades, spanning from dermatological disorders to its paradoxical effect as a fungicide in the treatment of immune compromised patients. Therefore, further clinical trials and animal testing are necessary to determine both the acute and the long-term pharmacokinetic and pharmacodynamic properties of CsA. Renal graft rejection is susceptible to both antigen-dependent and antigen-independent factors, ${ }^{2}$ but early histology cannot discriminate between the two conditions. ${ }^{5}$ In vitro studies have shown that CsA increases the intracellular $\mathrm{Ca}^{2+}$ concentration in proximal tubular cells, mesangial cells, and smooth vascular muscle cells, ${ }^{6,7}$ causing a subsequent increase in angiotensin II receptors. ${ }^{8}$ This effect may increase peripheral resistance ${ }^{9}$ and be responsible for the CsA-induced increase in systemic blood pressure. Treatment with CsA markedly affects the renin-angiotensin-aldosterone system in

From the MR Research Center (D.H.K., M.P., M.C.G.), Aarhus University Hospital, Skejby Sygehus, Aarhus, Denmark; Department of Endocrinology (A.F.), Aarhus University Hospital, Aarhus Sygehus, Aarhus, Denmark; Department of Renal Medicine (M.M.), Aarhus University Hospital, Skejby Sygehus, Aarhus, Denmark; and Clinical Institute (J.F., J.M.), Aarhus University Hospital, Skejby Sygehus, Aarhus, Denmark.

Address reprint requests to Daniel Hanefelt Kristensen, MR Research Center, Aarhus University Hospital, Skejby Sygehus, Brendstrupgårdsvej, DK-8200 Aarhus N, Denmark. E-mail: daniel.kristensen@mr.au.dk

(c) 2005 by Elsevier Inc. All rights reserved. 360 Park Avenue South, New York, NY 10010-1710 
parallel with an increase in the net tubular reabsorption or a decrease in secretion. Since tubular reabsorption is closely linked to medullary oxygen consumption, the aim of the present study was to investigate the intrarenal oxygenation in response to CsA. Blood oxygenation level-dependent magnetic resonance imaging (MRI) offers a unique noninvasive insight in renal tissue oxygenation changes followed by CsA treatment. Oxygen consumption in the tubules is closely linked to water reabsorption. Thus, the aim of this study was to investigate the long-term effect of CsA on renal oxygenation, and secondly, to measure the effect of CsA on renal blood flow and renal function.

\section{MATERIALS AND METHODS}

Adolescent mini Göttingen pigs $(n=8)$ were divided into two groups: (1) five pigs treated with a daily oral dose of CsA (10 $\mathrm{mg} / \mathrm{kg} / \mathrm{d}$ ) in a Neoral microemulsion and (2) three pigs functioning as controls. CsA in the micro emulsion was used because of its uniform pharmacokinetic profile virtually independent of diet and virtually independent of liver parameters. ${ }^{10,11} \mathrm{CsA}$ was given orally in the diet mornings and evenings. Animals were fully anesthetized during the experimental procedure. Premedication was performed with stresnil $(0.1 \mathrm{~mL} / \mathrm{kg})$ and dormicum $(0.1 \mathrm{ml} / \mathrm{kg})$, to hypnomidate $(0.25 \mathrm{~mL} / \mathrm{kg})$ to sedate for intubation, and anesthesia was maintained by ketalar infusion (6 to $8 \mathrm{mg} / \mathrm{kg} / \mathrm{h}$ ) and isoflurane ( $0.5 \%$ to $0.75 \%$ in $1: 2 \mathrm{O}_{2}: \mathrm{N}_{2} \mathrm{O}$ employed with a clinically approved MRI-compatible respirator). The study complied with the guidelines given by the local commission for experimental animal welfare. MRI was performed at baseline and at 5, 10, 15, 20, and 25 weeks after CsA treatment initiation using a Philips 1.5 T Gyroscan clinical system with a cardiac synergy-coil. The intrarenal oxygenation was indirectly measured from measurements of the R2* value using a multiecho gradient-echo sequence in the coronal plane, ${ }^{12,13}$ where R2* was defined as being the slope of the In(signal intensity) versus echo times curve and has shown to linearly correlate with the partial pressure of oxygen $\left(\mathrm{pO}_{2}\right)$ levels in renal tissue. ${ }^{13}$ Single kidney renal blood flow (skRBF) was measured by a velocitysensitive gradient-echo sequence in the sagittal plane. ${ }^{14}$ Renal volume was derived from a multislice gradient-echo sequence, followed by measurement of the time-activity curve in response to an intravenous bolus of Gd-DTPA bolus $(0.05 \mathrm{mmol} / \mathrm{kg})$. Relative single kidney glomerular filtration rate (rskGFR) was then estimated from the residual function derived after deconvolating an arterial input function with the glomerular (cortical) response curve as described by Pedersen et al. ${ }^{15}$ Differences between baseline and week 25 data were statistically evaluated using a paired Students $t$ test.

\section{RESULTS}

Cortical and medullar R2* values, skRBF and rskGFR, for the CsA-treated group and the control group are presented in Table 1. Comparing baseline (week 0) and end data (week 25) revealed that administration of CsA increased medullary R2* $(23.1 \mathrm{~Hz}$ vs $19.0 \mathrm{~Hz}, P=.002)$. Likewise, CsA increased cortical R2* $(13.3 \mathrm{~Hz}$ vs $12.3 \mathrm{~Hz}, P=.012)$. skRBF remained unchanged during the entire period (197.6 $\mathrm{mL} / \mathrm{min}$ vs $202.5 \mathrm{~mL} / \mathrm{min}, P>.05)$, whereas rskGFR increased significantly in the CsA group $(47.2 \mathrm{~mL} / \mathrm{min}$ vs $19.8 \mathrm{~mL} / \mathrm{min}, P=.005)$ in comparison to the control group $(30.2 \mathrm{~mL} / \mathrm{min}$ vs $20.2 \mathrm{~mL} / \mathrm{min}, P>.05)$.
Table 1. Mean Values of R2*, rskGFR, and skRBF During 0 to 25 Weeks of CsA Treatment

\begin{tabular}{lcccccc}
\hline Mean Values & $\begin{array}{c}\text { Week } \\
0\end{array}$ & $\begin{array}{c}\text { Week } \\
5\end{array}$ & $\begin{array}{c}\text { Week } \\
10\end{array}$ & $\begin{array}{c}\text { Week } \\
15\end{array}$ & $\begin{array}{c}\text { Week } \\
20\end{array}$ & $\begin{array}{c}\text { Week } \\
25\end{array}$ \\
\hline $\begin{array}{l}\text { Cortical R2* } \\
\quad \text { CsA }\end{array}$ & 12.3 & 12.5 & 13.3 & 13.2 & 13.7 & 13.3 \\
$\quad \begin{array}{l}\text { Control } \\
\text { Medullary R2 }\end{array}$ & 11.9 & 13.1 & NA & 12.0 & 12.2 & 12.6 \\
$\quad$ CsA & & & & & & \\
$\quad$ Control & 19.0 & 21.8 & 22.1 & 23.1 & 23.4 & 23.1 \\
rskGFR (mL/min) & 18.1 & 18.7 & NA & 18.7 & 19.2 & 19.1 \\
$\quad$ CsA & 19.8 & 20.2 & 23.5 & 37.6 & 41.8 & 47.2 \\
$\quad$ Control & 22.6 & 34.3 & NA & 37.0 & 33.7 & 30.5 \\
skRBF (mL/min) & & & & & & \\
$\quad$ CsA & 202.5 & 171.4 & 165.5 & 185.8 & 189.4 & 197.6 \\
$\quad$ Control & 207.6 & 206.8 & NA & 211.7 & 215.3 & 219.5 \\
\hline
\end{tabular}

All measurements were conducted with MRI.

\section{DISCUSSION}

The present study demonstrated that long-term treatment with CsA produces marked changes in the renal oxygenation and handling of blood. The significantly increased medully $\mathrm{R} 2 *$ is likely explained by an increased oxygen consumption in this part of the kidney, which is explained by an augmented tubular reabsorption of water. The indicated increased water reabsorption could be compensated for by an elevated rskGFR as demonstrated. Notably the oxygen supply was considered constant during the experimental period as indicated by an unchanged skRBF, supporting the view that a change in oxygenation may be the result of a change in renal work. The observed increase in rskGFR is not in accordance to the majority of previous CsA studies, ${ }^{2,16,17}$ although they have shown divergent results. CsA-induced renophysiological changes have furthermore been shown to differ among species. ${ }^{2,18-20}$ Comparably, hyperfiltration is occasionally seen in diabetic patients and animals prior to kidney damage, ${ }^{21-23}$ which raises the question about what would have happened beyond our experimental period of 25 weeks. Another important aspect is attributed to the administered concentration of CsA. The current study evaluated the long-term effect following $10 \mathrm{mg} / \mathrm{kg} / \mathrm{d}$ dosage of CsA. In clinics graft recipients are usually treated with a steady-state dosage of 10 to $15 \mathrm{mg} / \mathrm{kg} / \mathrm{d}$ CsA in the neoral emulsion. It should, however, be noted that we have observed severe renal damage using a CsA dosage of $30 \mathrm{mg} / \mathrm{kg} / \mathrm{d}$. Measurements in the present study were performed with MRI, which is known to be a well-proven modality for renal description. However, our findings were derived using analytical methods yet to be implemented into the clinics, and further experimental studies should reveal their precision as compared with conventional techniques (ultrasonography and radionuclides). One important aspect is the fact that calculated rskGFR may not be exactly equivalent to the glomerular filtration rate measured by inulin clearance.

In conclusion, the current study revealed some important renophysiological consequences of CsA on the kidney, 
which may be potentially important in further long-term studies. Nonetheless, further experiments seem necessary for an in-depth description of the complete array of renal effects following administration of CsA.

\section{REFERENCES}

1. Danovitch GM: Choice of immunosuppressive drugs and individualization of immunosuppressive therapy for kidney transplant patients. Transplant Proceed 31(suppl 1):2, 1999

2. Hansen JM: Cyclosporin A Nephrotoxicity in Renal Transplant Patients. Copenhagen: University of Copenhagen; 2003

3. Myers BD, Sibley R, Newton L, et al: The long-term course of cyclosporine-associated chronic nephropathy. Kidney Int 33:590, 1988

4. Tedoriya T, Keogh AM, Kusano K, et al: Reversal of chronic cyclosporine nephrotoxicity after heart transplantation-potential role of mycophenolate mofetil. J Heart Lung Transplant 21:976, 2002

5. Tullius SG, Tilney NL: Both alloantigen-dependent and -independent factors influence chronic allograft rejection. Transplantation 59:313, 1995

6. Gordjani N, Epting T, Fischer-Riepe P, et al: Cyclosporin-Ainduced effects on the free $\mathrm{Ca} 2+$ concentration in LLC-PK1-cells and their mechanisms. Pflugers Arch 439:627, 2000

7. Avdonin PV, Cottet-Maire F, Afanasjeva GV, et al: Cyclosporine A up-regulates angiotensin II receptors and calcium responses in human vascular smooth muscle cells. Kidney Int 55: 2407, 1999

8. Avdonin PV, Cottet-Maire F, Afanasjeva GV, et al: Cyclosporine A up-regulates angiotensin II receptors and calcium responses in human vascular smooth muscle cells. Kidney Int 55: 2407, 1999

9. Lo RA, Passaquin AC, Andre P, et al: Effect of cyclosporin A and analogues on cytosolic calcium and vasoconstriction: possible lack of relationship to immunosuppressive activity. Br J Pharmacol 118:885, 1996

10. Takahara S, Ohta K, Ohashi Y, et al: Comparative pharmacokinetic study of neoral vs sandimmun in Japanese stable renal allograft recipients. Transplant Proc 31:3089, 1999
11. Keown P, Niese D: Cyclosporine microemulsion increases drug exposure and reduces acute rejection without incremental toxicity in de novo renal transplantation. International Sandimmun Neoral Study Group. Kidney Int 54:938, 1998

12. Kone BC: A "BOLD" new approach to renal oxygen economy. Circulation 94:3067, 1996

13. Prasad PV, Edelman RR, Epstein FH: Noninvasive evaluation of intrarenal oxygenation with BOLD MRI. Circulation 94: 3271, 1996

14. Coulam $\mathrm{CH}$, Lee JH, Wedding $\mathrm{KL}$, et al: Noninvasive measurement of extraction fraction and single-kidney glomerular filtration rate with MR imaging in swine with surgically created renal arterial stenoses. Radiology 223:76, 2002

15. Pedersen M, Frøkiær J, Jensen F, et al: Quantitative measurement of renal function using contrast enhanced MRI. ISCORN meeting La Baule, France, May 2004

16. Youngelman DF, Kahng KU, Rosen BD, et al: Effects of chronic cyclosporine administration on renal blood flow and intrarenal blood flow distribution. Transplantation 51:503, 1991

17. Faulds D, Goa KL, Benfield P: Cyclosporin. A review of its pharmacodynamic and pharmacokinetic properties, and therapeutic use in immunoregulatory disorders. Drugs 45:953, 1993

18. Lassila M: Interaction of cyclosporine $\mathrm{A}$ and the reninangiotensin system; new perspectives. Curr Drug Metab 3:61, 2002

19. Kawai R, Mathew D, Tanaka C, et al: Physiologically based pharmacokinetics of cyclosporine A: extension to tissue distribution kinetics in rats and scale-up to human. J Pharmacol Exp Ther 287:457, 1998

20. Robson D: Review of the pharmacokinetics, interactions and adverse reactions of cyclosporine in people, dogs and cats. Vet Rec 152:739, 2003

21. Nielsen S, Hove KY, Dollerup J, et al: Losartan modifies glomerular hyperfiltration and insulin sensitivity in type 1 diabetes. Diabetes Obes Metab 3:463, 2001

22. Bak M, Thomsen K, Christiansen T, et al: Renal enlargement precedes renal hyperfiltration in early experimental diabetes in rats. J Am Soc Nephrol 11:1287, 2000

23. Christiansen T, Stødkilde-Jørgensen H, Flyvbjerg A: Magnetic resonance imaging as a monitor of kidney enlargement and regression in experimental diabetes in rats. J Endocrinol 153:193, 1997 